\title{
Aproximaciones al problema del lenguaje y las relaciones intersubjetivas en Sartre ${ }^{*}$
}

\author{
Cedric Steinlen ${ }^{* *}$
}

\begin{abstract}
Resumen
El siguiente artículo tiene como objetivo identificar cómo se lleva a cabo en la obra de Sartre el análisis sobre el fenómeno del lenguaje. Particularmente, nos situaremos en el problema de las relaciones intersubjetivas y su relación con el lenguaje. Esto lo haremos interpretando los postulados sobre esta temática, específicamente desde La náusea, El ser y la nada y la Crítica de la Razón dialéctica. Esto nos permitirá situar el pensamiento de nuestro autor en el contexto de la filosofía contemporánea.
\end{abstract}

Palabras clave: Sartre, lenguaje, intersubjetividad, fenomenología, marxismo.

\begin{abstract}
The following article has as aim identify how the analysis is carried out in Sartre's work on the phenomenon of the language. Particularly, we will place in the problem of the intersubjective relationships and his relation with the language. We will do this interpreting the postulates on this subject matter, specifically from The nausea, The being and nothing and the Critique of the dialectical Reason. This will allow us to place the thought of our author in the context of the contemporary philosophy.
\end{abstract}

Keywords: Sartre, language, intersubjective, phenomenology, marxism.

\footnotetext{
* Este artículo fue reelaborado a partir de una ponencia realizada en el Simposio Hermeneia-2015 en la Universidade Federal de Santa Catarina (Florianópolis, Brasil). Recibido: abril 2016. Aceptado: julio 2016.

** Universidade Federal de Santa Catarina. Florianópolis, Brasil. Email: cedric.steinlen1@gmail.com
} 


\begin{abstract}
Descubrí el mundo a través del lenguaje, pero durante mucho tiempo tomé el lenguaje por el mundo. Existir era poseer una denominación controlada en alguna parte de las tablas infinitas del Verbo.
\end{abstract}

J. P. Sartre, Las palabras, 1963.

\title{
1. Introducción
}

En el presente artículo nos proponemos analizar cuál es el papel que juega el problema del lenguaje en la obra filosófica y literaria de Jean-Paul Sartre, para este propósito estudiaremos algunas de sus obras, que abarcan parte de sus trabajos más importantes, en donde abordó este fenómeno. Aunque se refiere escasamente a este tema y, por lo general a propósito de otras cuestiones, existe evidencia en estas obras que sirven para alcanzar una visión de conjunto que permite establecer un hilo conductor en relación a sus proposiciones sobre el problema del lenguaje y su relación con la intersubjetividad. Específicamente, se analizarán una de sus más famosas novelas La náusea (1938): obra que se anticipa a las temáticas y problemas de su trabajo filosófico posterior; El ser y la nada (1943): obra filosófica fundamental del existencialismo del siglo XX; y la Crítica de la razón dialéctica (1960): trabajo con el cual Sartre quiso plantear un diagnóstico de los problemas teóricos del marxismo para fundar una nueva razón dialéctica. La elección de estas tres obras tiene relación con la influencia que éstas alcanzaron en la filosofía del siglo XX, que sin lugar a dudas fue marcado fuertemente por existencialismo sartreano: "Por lo que concierne a Sartre pensador (...) su significación consiste en haber tratado de construir la más radical filosofía de la libertad que hasta hoy haya aparecido en la historia de la filosofía" (Bobbio: 1997, p. 86). Nuestro análisis se dividirá en tres capítulos que presentan el tratamiento del problema del lenguaje y la intersubjetividad en tres etapas de la producción filosófica de Sartre: literaria, fenomenológica y marxista.

Nuestras preguntas de investigación son: ¿Cuál es el papel que ocupa el problemas del lenguaje en la filosofía de Sartre? ¿Qué importancia tiene el lenguaje en las relaciones intersubjetivas?. La hipótesis de trabajo es: que el fenómeno del lenguaje sería una preocupación filosófica en Sartre, que atraviesa por diferentes períodos de su obra. Aún cuando, este fenómeno no habría sido tratado con una extensión y profundidad considerable, si tendría importancia en su filosofía como articulador y fundamento de las relaciones intersubjetivas. Consideramos de gran relevancia introducirnos al análisis del problema del fenómeno del lenguaje en Sartre, para que de esta manera se pueda abordar su pensamiento desde la perspectiva de la filosofía contemporánea que, desde el giro lingüístico, el leguaje ha tenido una preponderancia considerable de una manera general en las discusiones filosóficas, y que llevó a cabo un cambio metodológico que postula que el trabajo de 
la filosofía actual no puede lograrse sin un análisis previo del problema del lenguaje: "Nada se ha vuelto más importante para la filosofía en estos dos últimos siglos que explorar, desde el lenguaje y con el lenguaje, las nuevas bases, los nuevos fundamentos que están sirviendo de soporte al pensamiento occidental de este tiempo" (López: 2011, p. 190). Si bien, nuestra intensión, en ningún modo es situar a la filosofía existencialista en el contexto del denominado giro lingüístico, si pretendemos interpretar los posibles puntos que se puedan conectar entre ambas corriente. Así, al analizar esta problemática en la filosofía sartreana, podremos situar el lugar que ocupa este pensamiento en la historia de la filosofía y realizar una interpretación de su obra desde los conceptos de la filosofía actual.

\section{La literatura y lenguaje}

Sartre en 1938, tras una estancia en Berlín donde estudió la fenomenología de Husserl y luego de escribir la Trascendencia del ego (ensayo fenomenológico donde intenta superar el solipsismo husserliano), escribe su primer gran éxito literario: La náusea. Tanto en las novelas, como en las obras de teatro y en los ensayos políticos, Sartre plasmó su pensamiento filosófico utilizando metáforas o simplemente llevando las densas concepciones filosóficas al ámbito literario. Por este motivo, quien desee comprender las tesis existencialistas deberá acudir a las novelas de Sartre, ya que llevan a cabo, de manera estética, sus teorías filosóficas. La herramienta de la literatura le sirvió a nuestro autor para que el existencialismo, que se encontraba desde Kierkegaard hasta Heidegger oculto en la erudición de la academia, saliera al mundo del hombre común. Así, lo hace notar Guillermo de Torre en el prólogo al libro El Muro: "Si el existencialismo en cuanto cosmovisión filosófica (...) no había rebasado el ámbito profesional, ha bastado que fuera exhibido sobre la plataforma espectacular propia de las doctrinas literarias (...) para acaparar las atenciones más distantes" (Sartre: 1962, p. 7). Sartre siendo un filósofo, realizó una reflexión crítica en torno a su producción literaria desde la estética filosófica. Esto lo podemos ver expuesto en una obra de 1948 llamada ¿Qué es la literatura?, en ésta reproduce de manera brillante la labor del escritor comprometido y entrega trazos de una concepción lingüística en relación al lenguaje: "El escritor trabaja con significados (...) Sólo el significado puede dar a las palabras su unidad verbal (...) El que habla está situado en el lenguaje, cercado por las palabras; éstas son prolongaciones de sus sentidos (Sartre: 1967, pp. 45-46). Sartre con esta obra demuestra que no sólo hizo literatura, sino que justificó teóricamente lo que hacía:

Esta posición lo llevó a elaborar toda una doctrina estética, es decir, una concepción doctrinal sobre el ser y quehacer del arte literario: qué se entiende por literatura y por qué, cuál es su importancia y cuáles sus limitaciones. Estas ideas tuvieron tanta resonancia en el ámbito cultural e intelectual de varias generaciones como su producción literaria misma (Mora: 2007, p. 112). 
En algunos casos como la novela La náusea encontramos la base de la posterior reflexión de su filosofía existencialista, en esta novela utiliza de manera metafórica nociones que podemos identificar como cercanas a la fenomenología de Husserl y a la hermenéutica de Heidegger, ideas que venía trabajando desde su estancia en Berlín unos años antes. Ahora bien, de La náusea nos interesan sólo escasos pasajes que tratan la cuestión del lenguaje y la intersubjetividad, como veremos éstos se construyen a través de una especie de reducción fenomenológica al estilo del método husserliano y acompañado de matices de la interpretación que hace Heidegger sobre el lenguaje durante la década de $1930^{1}$. En un párrafo de La náusea donde Antoine Roquentin -el personaje principal de la novela- descubre cuál era la fuente del sentimiento de miedo que le agobia, Sartre expone algunas concepciones filosóficas fundamentales de su existencialismo con el hincapié puesto en el fenómeno del lenguaje desde la perspectiva lingüística:

[...] hace un rato estaba yo en el jardín público. La raíz del castaño se hundía en la tierra exactamente debajo de mi banco. Yo ya no recordaba qué era una raíz. Las palabras se habían desvanecido, y con ellas la significación de las cosas, sus modos de empleo, las débiles marcas que los hombres han trazado en su superficie (Sartre: 2005, p. 209).

En este pasaje se describe de forma literaria una especie de reducción fenomenológica de la cosa (raíz), a tal extremo que no sólo se pone entre paréntesis el conocimiento previo que se tiene de la raíz, sino que va más allá al disolverse la palabra raíz y con ello su significado. El personaje se encuentra en el mundo, pero es un mundo de sensaciones y no de significados, las palabras que otorgan significación a las cosas se han desvanecido y con ellas los conceptos. Luego, al eliminar la puesta en paréntesis de la cosa, esa sensación que experimentó surte sentido a través del lenguaje: "la palabra Absurdo nace ahora de mi pluma; hace un rato en el jardín, no la encontré, pero tampoco la buscaba, no tenía necesidad de ella; pensaba sin palabras, en las cosas, con las cosas" (Sartre: 2005, p. 212). Roquentin, había experimentado un mundo en el cual él era una cosa más entre todas las cosas, sin que estas tuvieran sentido a través del lenguaje, sino sólo como mera existencia, dentro de la cual él estaba sumergido. Luego al surgir la palabra absurdo se descubre el sentimiento de náusea que alude a estar arrojado en el mundo. Así, las palabras aparecen y construyen un mundo de cosas que se llenan de significados, los fenómenos no aparecen sólo como apariencias vacías en el medio de la existencia, desbordan el sentido que el hombre les ha dado a través el lenguaje. De este modo, cuando Roquentin habla de su soledad y completa apatía con los demás, se refiere al fenómeno del lenguaje como creador de mundo: "Ahora ya no pienso en nadie; ni siquiera me cuido de buscar palabras (...) La mayor parte del tiempo, al no unirse a palabras, mis pensamientos quedan en nieblas. Dibujan formas vagas y agradables, se disipan; en seguida las olvido (Sartre:

\footnotetext{
${ }^{1}$ Referencias a las nociones de lenguaje en Heidegger las analizaremos en el siguiente capítulo.
} 
2005, p. 212). Aquí, desde el enfoque de la lingüística, observamos como al diluir el signo o concepto que se encuentra en las palabras, se desvanece la representación que se tiene del objeto. Si bien, Sartre no hace referencia a la lingüística en su obra en general, podríamos sugerir que en esta narrativa podemos encontrar ideas cercanas a Chales S. Peirce:

E1 signo, como se ha dicho, representa a su objeto, pero no se hace bajo todos los aspectos, sino que está en lugar de él sólo con referencia a una suerte de idea. A esta idea Peirce la llama fundamento del representamen. EI fundamento debe entenderse en e1 mismo sentido que cuando se dice 'un hombre capta a idea de otro hombre; esto es, no se capta la idea idéntica del otro hombre, pero si se tiene una idea similar (von der Walde: 1990, p. 91).

Otra de las dimensiones que nuestro autor aborda en La Náusea y que será tema de su obra filosófica posterior, es la importancia que da a la mirada que se percibe en su obra literaria. La mirada tendrá un lugar importante desde la perspectiva de las relaciones intersubjetivas, de hecho, como veremos más abajo, en El ser y la nada le otorga un considerable análisis a esta cuestión. Volviendo a La Náusea, la metáfora de la mirada la utiliza desde la perspectiva del sentimiento de vergüenza ante una acción indecorosa. En este caso, se trata del personaje del Autodidacta, que es sorprendido por Roquentin realizando un acto impropio con un menor de edad en la biblioteca donde trabaja, la cual el personaje principal frecuenta: "Me volví hacia el Autodidacta, que al fin se había levantado. Pero evitaba mi mirada; con la cabeza baja, fue a colgar su abrigo (...) Alcancé al Autodidacta al pie de la escalera. Me sentía incómodo, avergonzado de su vergüenza, no sabía que decirle" (Sartre: 2005 , p. 274). Lo que Sartre quiere ejemplificar, desde la perspectiva de la intersubjetividad y el lenguaje, es que la mirada inquisidora del Otro determina al individuo observado, hace que éste se configure a partir de ese juicio. $\mathrm{Al}$ acontecer esto, surge el sentimiento de vergüenza; la vergüenza revela la mirada del prójimo, "es reconocimiento de que efectivamente soy ese objeto que otro mira y juzga" (Sartre 1998, p. 337). En fin, en el siguiente capítulo podremos comprender mejor estos conceptos literarios del existencialismo, a partir de una explicación filosófica sistemática.

\section{El período fenomenológico}

Unos años después en su obra El ser y la nada, nuestro autor formula una visón sui generis de la reducción fenomenológica de Husserl. Sartre se habría empeñado en erradicar los determinismos de toda clase en el hombre, el hombre era un ser proyectándose desde su haber sido de absoluta determinación hacia la libertad absoluta. Este ser humano arrojado hacia posibilidades originales e indeterminadas, no tenía en la concretización de su proyecto ninguna esencia que lo precediera. Para Sartre la libertad es un telos ( $\tau \dot{\lambda} \lambda \mathrm{o}$ ) del proyecto individual humano, esto significa que el hombre hace de sí mis- 
mo lo que su libre voluntad le guíe. Si la existencia del hombre arrojado en el mundo precede a su esencia, entonces la esencia del hombre es lo que éste hará de sí mismo:

La reflexión fenomenológica de El ser y la nada se halla focalizada en la conciencia singular que todavía no ha sido capaz de abandonar su propio subjetivismo. Dicho proceder parte del supuesto, no cuestionado en modo alguno, de que toda conciencia vendría a ser conciencia de un objeto y todo objeto es objeto para una conciencia (...) Dicha relación necesaria, establecida entre la conciencia y el objeto correspondiente, recibía el nombre de intencionalidad en lo expuesto a lo largo del discurso argumentativo esgrimido con rigor y precisión en Cartesian Meditations de Edmund Husserl. (Higuero: 2008, pp. 57-58).

Sartre, se propone la tarea de efectuar una descripción ontológica del ser del fenómeno, es decir develar al ser que se encuentra en los fenómenos: "el ser del fenómeno, aunque coextensivo al fenómeno, debe escapar a la condición fenoménica" (Sartre: 1998, p. 17). En esta obra, nuestro autor trabaja el problema del lenguaje -ahora desde el rigor del método filosófico- para analizar las relaciones con el prójimo y efectuar una descripción ontológica del ser de ese fenómeno (intersubjetividad). Este desvelamiento lo realiza desde un perspectiva óntica, es decir a través de la descripción de actitudes concretas de tal o cual ser humano con el prójimo como el amor, el odio, etc. La experiencia del otro descrita en El Ser y la Nada es la que comparece algo delante de mí como un objeto que me hace parte como uno más de los objetos del mundo. Así, la presencia del otro significaría un sujeto que me constituye como objeto y viceversa: "El surgir de otro sujeto en mi experiencia es mi devenir objeto para el otro y tener conciencia de mí mismo como objeto por la mediación de otra conciencia" (Alves: 2012, p. 12). El prójimo es un mediador entre mí y mí mismo, es decir, que reconozco que soy como el prójimo me ve. Soy para otro cuando mi subjetividad se experimenta como objeto para otra. En este sentido, se puede establecer que el presupuesto del lenguaje está en la intersubjetividad, ya que a través del lenguaje paso a ser objeto para otro.

El otro me reconoce de una forma en la cual jamás podré reconocerme yo mismo: como un objeto que está frente a él. Sartre sostiene que, en la dimensión del para-sí, el cuerpo se presenta como punto de vista sobre el cual no puede haber punto de vista alguno; sin embargo, al estar frente a otro surge una nueva dimensión: el cuerpo se vuelve para-otro. Mi cuerpo es visto y ese "ser visto" es algo que me resulta inalcanzable; me encuentro alienado de mi propio cuerpo (Basilio: 201, p. 45).

Estas relaciones concretas hacia el otro son articuladas por el lenguaje, es por este motivo que nuestro autor aborda este problema y lo analiza. Para esto dedica una parte del capítulo sobre las relaciones concretas con el prójimo de El ser y la nada. Sartre establece que el lenguaje forma parte de la 
condición humana, ya que es originariamente la posibilidad de que un para-sí experimente su para-otro: "El lenguaje no es un fenómeno sobre agregado al ser-para-otro; es originariamente el ser-para-otro, es decir, el hecho de que una subjetividad se experimente así misma como objeto para el otro" (Sartre: 1998, p. 465). Es decir, que el surgimiento del otro frente a mí como mirada hace surgir el lenguaje como condición de mi ser. El ser-para-otro tiene como fundamento el ser-para-sí, es decir que la existencia del prójimo es experimentada desde mi conciencia como un ser-objeto en medio del mundo: "El prójimo es siempre ahí, presente y experimentado por mí como aquello que da al lenguaje su sentido. Cada expresión, cada gesto, cada palabra es, de mi parte, un experimentar concreto de la realidad alienadora del otro" (Sartre: 1998, p. 466). Aquí se observa como el lenguaje juega el papel de otorgarle significación al mundo, con las palabras no sólo se interpreta el mundo, también se generan los lasos con el prójimo a través del reconocimiento de este como intersubjetividad del Para-otro. El ser humano aparece como ser-paraotro, el otro se aparece a la conciencia a través de la mirada, así la presencia del otro aparece como necesidad, ya que ese otro me convierte en en-sí. Cuando el otro me mira me transforma en objeto en ser-en-sí y cuando el lenguaje se instaura en mi por la mirada del otro paso a ser lenguaje:

El poder de la mirada del otro sobre mí es substancial y básicamente, me controla, define y asegura mi existencia. Sartre usa el ejemplo del acto vergonzoso para ilustrar su concepción de existencia humana. El filósofo dice que cuando se comete un acto vergonzoso, por ejemplo, mirar a través de la cerradura de una puerta, la persona está consciente del acto que está cometiendo y de nada más. La persona deja de existir, solo existe el acto, la persona es el acto. Según Sartre, este acto vergonzoso no es culpa de nadie, la situación simplemente existe. Sin embargo, todo cambia si yo soy atrapado cometiendo ese acto vergonzoso. La mirada del Otro sobre mí cuando cometo ese acto, de pronto me devuelve la existencia. Yo soy visto, yo existo, y más importante, yo soy juzgado. De pronto, yo soy culpable y siento vergüenza. Esta vergüenza procede de la percepción que el Otro tiene de mí, él o ella me juzga (Lloyd: 2014, p. 116).

En relación a la importancia que juega el leguaje para las investigaciones ontológicas, Sartre parece estar totalmente de acuerdo con Heidegger. En El ser y la nada sostiene que: "Heidegger tiene razón al declarar que soy lo que digo" (Sartre: 1998, p. 465). Lo que quiere decir con este acuerdo, es que todo lo que somos solo lo podemos enunciar a través del lenguaje. Para Heidegger el problema ontológico del lenguaje tiene un lugar relativamente importante desde la perspectiva de la relación con el prójimo. En este sentido, Sartre declara que su propia concepción de lenguaje la toma de una obra menor de Heidegger de 1937 denominada Hölderlin y la esencia de la poesía. En esta obra, Heidegger aborda el problema del lenguaje a partir de la poesía de Hölderlin, se refiere en ésta a que el habla no es un instrumentos entre otros que tiene el hombre que lo definen como tal, sino que es el que garantiza la posibilidad de la comprensión de encontrarse lanzado en el mun- 
do: "Sólo hay mundo donde hay habla (...) aquel acontecimiento que dispone la más alta posibilidad de ser hombre" (Heidegger: 2002, pp. 132-133). En esta obra de Heidegger -que Sartre conoce bien en el momento de escribir El ser y la nada-, establece que con el lenguaje damos significado al mundo, es decir, que sólo a partir del diálogo nos representamos el mundo, a través del él podemos hacer patente la experiencia de ser-en-el-mundo. A partir de esta interpretación sobre el lenguaje que hace Sartre, configura la idea de que todo lo que se encuentra en la totalidad de la realidad o todo lo que es el ser-enel-mundo como ser-para-otros sólo se puede articular a través del lenguaje: "Forma parte de la condición humana (...) El surgimiento del otro frente a mí como mirada hace surgir el lenguaje como condición de mi ser" (Sartre: 1998, p. 465). Sartre describe el lenguaje como el articulador de las relaciones con el prójimo, pues esas actitudes cobran sentido con en lenguaje, más aún, dice "son el lenguaje, o, si se quiere, uno de sus modos fundamentales" (Sartre 1998, p. 465). El lenguaje supone la relación con los otros y a través de él se configura la realidad del mundo absurdo en el cual el hombre es arrojado.

\section{El giro al marxismo}

Tuvo que suceder un hecho histórico tan sangriento y desgarrador como la Segunda Guerra Mundial para que Sartre dejara la ontología y se comprometiera con el materialismo histórico: "lo que hizo que saltase el envejecido marco de nuestro pensamiento fue la guerra, la ocupación, la resistencia, en los años que siguieron queríamos luchar al lado de la clase obrera, comprendimos por fin que lo concreto es la historia y la acción dialéctica" (Sartre: 1995, p. 27). De esta forma, Sartre se acerca al marxismo y él se convertirá en un intelectual comprometido, bajo algunas premisas del existencialismo de su primera etapa que hemos sintetizado más arriba. Nuestro autor, habría llevado a cabo en su obra Crítica de la razón dialéctica el proyecto de renovar al marxismo a partir de su existencialismo. En la introducción de esta obra comienza estableciendo su acuerdo de principio con el materialismo histórico, él declara estar convencido de que la dialéctica es una herramienta adecuada para comprender la historia concreta de los hombres. El método que propone parte de la concepción marxista de que la materialidad condiciona la vida social en un mundo marcado por la escasez que prefigura y condiciona al hombre en un grupo o clase: "El descubrimiento capital de la experiencia dialéctica (...) es que el hombre está mediado por las cosas" (Sartre: 1995, p. 211). Así, el proyecto individual humano -que es la búsqueda de la libertad- está en constante contradicción con la condiciones materiales que lo condicionan, ésta es la primera negación del proceso dialéctico: "Toda dialéctica histórica descansa sobre la praxis individual en tanto en que esta es ya dialéctica, es decir, en la medida en que la acción es por sí misma superación negadora de una contradicción " (Sartre: 1995, p. 212). El ser humano se encuentra en un mundo material, desde que nace en está condicionado por la materialidad o exterioridad. Para alcanzar la libertad debe utilizar al mundo que se caracteriza por su escasez, y en este mundo se encuentra con otros que están buscando 
sus propios fines. Es decir, que se ve condicionado por un mundo material que limita su proyecto individual objetivándolo en un grupo o clase social. En este contexto, las relaciones humanas aparecen como mediación entre los distintos sectores de la materialidad y se realizan bajo ciertas condiciones sociales e históricas:

Serán los raciocinios de Crítica de la razón dialéctica, los que, de hecho, ponen de relieve una pronunciada distancia manifiesta respecto a la reflexión fenomenológica focalizada en la conciencia, recogida en El ser y la nada, al tiempo que se intenta sin disimulo ocultador y abiertamente la construcción de una teoría grupal desde la perspectiva metodológica del marxismo. (Higuero: 2008, p. 64).

Nuestro autor retoma, bajo este enfoque marxista, la problemática analizada en el capítulo anterior en alusión al lenguaje y las relaciones intersubjetivas, que se desarrollan a través de un proceso dialéctico e histórico: "las relaciones históricas son humanas en la medida en que se dan en todo momento como la consecuencia dialéctica de la praxis, es decir, de la pluralidad de actividades (...) Es lo que muestra muy bien el ejemplo del lenguaje” (Sartre: 1995, p. 230). El lenguaje articula la diversidad de acciones de los hombres encaminadas a la realización de prácticas humanas individuales que se desarrollan en este movimiento dialéctico, que buscan establecer la libertad pero alienadas bajo las contradicciones de clase. Para Sartre, el lenguaje forma parte de esa dialéctica, es un fenómeno más de la materialidad de la realidad, es un objeto más:

La palabra es materia. En apariencia (una apariencia que tiene su verdad en tanto que tal) me golpea materialmente, como un sacudimiento de aire que produce determinadas conmociones en mi organismo, particularmente determinados reflejos condicionados que la reproducen en mí en su materialidad (lo oigo al hablarlo en el fondo de la garganta) (Sartre: 1995, p. 230).

Ese fenómeno material que es el habla, le permite al hombre interpretar las condiciones de vida en la que se encuentra y unificar las diversas experiencias que van desenvolviendo su contexto histórico, la palabra: "transporta hacia mí los proyectos del Otro y hacia el Otro mis propios proyectos. No cabe duda de que se podría estudiar el lenguaje de la misma manera que la moneda: como materialidad circulante, inerte, que unifica dispersiones" (Sartre: 1995, p. 230). En esta obra, el lenguaje aparece analizado como fundamento de la relación con el prójimo, este le otorga significado a un mundo histórico que va mudando el sentido que se le dan a las cosas: "las palabras viven de la muerte de los hombres, se unen a través de ellos; en toda frase que yo forme, se me escapa el sentido, me lo roban; cada día y cada 'hablador' altera los significados para todo, los otros vienen a cambiarlos hasta en mi boca" (Sartre: 1995, p. 230). El lenguaje es parte de la historia que está en marcha, es mate- 
rialidad en curso. En las palabras se reflejan la complejidad de las relaciones dialécticas, los diálogos, los enfrentamientos, las contradicciones y de estos dependerán el significado que se les den a las cosas.

El fenómeno del lenguaje expresado a través del habla y captado en un instante de un momento preciso del desarrollo histórico, sería una síntesis de la significación de la realidad histórica de las relaciones dialécticas de los hombres: "No cabe duda de que en cierto sentido el lenguaje es una totalidad (...) Pero esta totalidad fundamental no puede ser nada si no es la praxis misma en tanto que se manifiesta directamente a otro" (Sartre: 1995, pp. 230231). Esta práctica del hombre en un mundo material marcado por las contradicciones se expresa en un contexto social y en éste las relaciones intersubjetivas se experimentan a partir del significado del mundo que nos ha otorgado el lenguaje: "El lenguaje es praxis como relación práctica de un hombre con otro y la praxis siempre es lenguaje (tanto si miento como si dice la verdad), porque no puede hacerse sin significarse" (Sartre: 1995, p. 231). El lenguaje como praxis sería un significante o un componente material de signos lingüísticos que tienen la función de apuntar hacia el significado o representación del concepto de los fenómenos del mundo que están a la mano y que aparecen en nuestra conciencia. Pero para que el individuo pudiera concebir esos significados debió adquirirlos mediante el diálogo con los otros que conforman la sociedad y la historia: "para que se integre a cualquier empresa colectiva, es necesario que su relación con otro, tal y como se expresa por y en la materialidad del lenguaje, le constituya en su realidad misma" (Sartre: 1995, p. 231). De esta manera, la historia se construye a partir del diálogo que va transfigurando el significado del mundo en medio de las contradicciones en que se ven envueltos unos y otros, en medio de una totalización dialéctica en marcha: "de hecho, las 'relaciones humanas' son estructuras interindividuales cuyo lazo común es el lenguaje y que existen en acto en cada momento de la Historia" (Sartre: 1995, p. 231). El lenguaje es la historia, no hay historia sin los hombres con su diálogo en medio de las contradicciones del mundo material, y con el cual han dado sentido y continúan dando sentido a ese mundo escaso en que se encuentran lanzados hacia su libertad individual, pero que se ve interrumpida por la contradicción de enfrentarse con la necesidad.

\section{Conclusión}

En las investigaciones sartreanas sobre las relaciones concretas con el prójimo se sostiene que: en las diversas tentativas de captar aquellas relaciones, siempre el lenguaje es el articulador de todas ellas, tanto en el período fenomenológico como en el marxista, ya que en la intersubjetividad el reconocimiento del prójimo y del mundo se dan por el lenguaje. Sartre le dedica una pequeña extensión a este problema tanto en La Náusea, El Ser y la Nada y en la Crítica de la razón dialéctica. En La Náusea, esboza a partir de su estética literaria los gérmenes de sus posteriores conclusiones filosóficas, de una manera extraordinaria elabora las nociones del lenguaje y las relaciones concretas con el prójimo. En El Ser y la Nada, sostiene que el lenguaje ac- 
túa como el articulador de las relaciones con el prójimo, pues las actitudes que analiza fenomenológicamente cobran sentido a través del en lenguaje. Estas son las relaciones concretas con el prójimo como el amor, el deseo o el odio, que se articulan a través del lenguaje, de ahí la importancia que se da a este fenómeno en sus investigaciones. El lenguaje supone la relación con los otros y a través de este configuro la realidad del mundo. En la Crítica de la razón dialéctica, el proyecto individual encuentra su verdad histórica en la totalización dialéctica. De esta manera, el filósofo francés pretende descubrir en el movimiento dialéctico la verdad de las relaciones sociales de los seres humanos. Es decir, esta razón dialéctica sólo se puede descubrir en la historia de los hombres, la cual se desenvuelve sobre una estructura material que los condiciona. En esta experiencia dialéctica el hombre se encuentra en una contradicción entre la libertad individual, los otros (la sociedad) y la escasez de la materialidad, éstas son las que configuran la verdad de la historia universal, que al final está determinada por el significado del mundo que otorga el lenguaje. Cada práctica individual es fundamentada por una historia colectiva que desemboca en el lenguaje, y a su vez este lenguaje conforma la significación de una sociedad. Es decir, que el proceso histórico-dialéctico está conformando en su totalidad por el lenguaje que permite su inteligibilidad.

A partir de nuestras observaciones, podemos concluir que Sartre mantuvo un hilo conductor en su análisis en relación a su interés por el fenómeno del lenguaje en algunas de sus principales obras analizadas en este trabajo. Es por este motivo, que pensamos que es pertinente tomar en cuenta esta problemática en el momento de situar a nuestro autor en el contexto de la discusión filosófica contemporánea sobre el lenguaje, a pesar de la precariedad de su tratamiento en dichas obras. Sostenemos que, si bien esta problemática no está inmersa en la discusión principal las obras estudiadas, su análisis no deja de tener una relativa importancia en su filosofía en general. Esto se debe a que en todos los casos analizados en los diferentes escritos, siempre el fundamento de las relaciones con el prójimo es el lenguaje. En este sentido, sostenemos que es posible realizar una interpretación adecuada de su filosofía, partiendo de éstas problemáticas, que están presentes en la discusión filosófica contemporánea. De este modo, podremos realizar una reinterpretación de sus obras clásicas, a partir de una mirada actualizada, es decir, desde el paradigma de la filosofía actual. Creemos, que de esta forma, se podrá aportar a un análisis actualizado del existencialismo, que en las últimas décadas ha quedado relegada a un segundo plano en las discusiones académicas. 


\section{Referencias bibliográficas}

Alves, Pedro: "Empatía y ser-para-otro. Husserl y Sartre ante el problema de la intersubjetividad", Revista investigaciones fenomenológicas, 2012, $\mathrm{N}^{\circ} 9$.

BASILIO, Maximiliano: "Ontología e intersubjetividad desde el debate Sartre/ Merleau-Ponty", Revista Devenires, 2012, № 25-26.

Boввio, Norbert. (1997): El existencialismo. Santiago: Fondo de cultura económica.

HeIDEgGER, Martin. (2002): Arte y poesía. México: Fondo de cultura económica.

Higuero, Francisco: "Intersubjetividad y teoría grupal en el pensamiento de Sartre", Revista de Filosofia Convivium, 2008, № 21.

LÓPEZ, Frank: "El giro lingüístico de la filosofía y la historiografía contemporánea", Revista Mañongo, 2011, N 37.

LLOYD, Andrew: "La mirada sartriana: poder y otredad en L'Être et le Néant, La Nausée y Huis clos", Revista Letras, 2014, № 55.

Mora, Arnoldo: "Filosofía y literatura en Sartre", Rev. Filosofía Univ. Costa Rica, 2007, 우 114.

Sartre, Jean-Paul. (1995): Crítica de la razón dialéctica. Tomo I; libro I. Buenos Aires: Editorial Losada.

SARTRE, Jean-Paul. (1967): Qué es la literatura?. Buenos Aires: Editorial Losada,

SARTRE, Jean-Paul. (1962): El muro. México, D. F.: Editorial Diana.

SARTRE, Jean-Paul. (1998): El ser y la nada: ensayo de ontología fenomenológica. Buenos Aires: Editorial Losada.

SARTRE, Jean-Paul. (2005): La náusea. Buenos Aires: Editorial Losada.

SARTRE, Jean-Paul. (1997): Las palabras. Buenos Aires: Editorial Losada.

VON DER WALde, Lillian: “Aproximación a la semiótica de Charles S. Peirce”, Revista de teoría y análisis Acciones textuales, 1990, № 2 . 